\title{
Robert Frank e a História das Relações Internacionais. Balanço e manifesto
}

Robert Frank y la Historia de las Relaciones Internacionales. Inventario y manifiesto

Robert Frank and the History of International Relations. Reappraisal and manifesto

Robert Frank et l'histoire des relations internationales. Bilan et manifeste

Alexandre Luis Moreli Rocha[1]

FRANK, Robert (org.). Pour l'histoire des relations internationales. Paris: PUF, 2012.776 p. 
balanço reexamina o estado atual da pesquisa sobre as tais "forças" em um livro longo de 776 páginas organizadas pelo professor Robert Frank, sucessor de Renouvin, Duroselle e Girault na Sorbonne.

Em um momento no qual outras escolas nacionais lançam reflexões sobre o estado da disciplina, fazendo referência à contribuição francesa, ${ }^{3}$ Frank aponta para a necessidade de os herdeiros de Renouvin refletirem sobre o estado de suas pesquisas e, para não ficarem pelo caminho, de "cultivarem seu próprio jardim" (p. XIV).

Se a revolução epistemológica do surgimento da HRI havia mostrado o quão míope estava o ponto de vista da História Diplomática, a disciplina ainda evoluiria ao descobrir que seria preciso não somente valorizar as relações dos homens de Estado com a sociedade e suas forças profundas, mas também entender as dinâmicas internacionais de fatores econômicos, geoestratégicos, culturais e da chamada "mentalidade coletiva", tanto dentro como fora dos governos.

De fato, a renovação de Renouvin e Duroselle, ao estabelecer que as relações entre os povos "podem raramente ser dissociadas das que são estabelecidas entre os Estados", que, por sua vez, tornar-se-iam o "centro das relações internacionais", ${ }^{4}$ precisava vencer novas barreiras. Frank, claramente marcado pela invasão do Iraque em 2003 e pelo desenrolar da primavera árabe e das operações na Líbia, elege a democracia, entre outros temas, para guiar a organização dos capítulos e mostrar que o homem se tornou, para o historiador das relações internacionais, a perspectiva essencial no trato do tema (p. XII, p. 57, p. 211, p. 687-696).

Dividido em cinco grandes partes (em um total de 30 capítulos), o livro percorre, em um primeiro momento e de modo introdutório, o estado da arte em diversas escolas nacionais de HRI para, na segunda parte e de forma atualizada, discutir como o historiador deve enfrentar a análise dos diversos níveis nos quais as relações humanas se dão, na época contemporânea, através das fronteiras: do nacional ao transnacional, passando, sem surpresa, pelo internacional. A terceira parte retoma as concepções de forças profundas de Renouvin para investigar se, por quais razões e como elas são hoje trabalhadas pela historiografia francesa. A penúltima parte recupera as reflexões que Duroselle deixou marcadas, em 1964, na segunda parte da Introduction, para ressaltar a atualidade dos estudos dos processos de tomada de decisão em política externa. Finalmente, revelando não só uma realidade política, mas também historiográfica do continente, pois absorvendo desde os anos 1980 muito dos esforços dos historiadores franceses, a quinta e última parte é dedicada à Europa, às questões específicas ligadas às relações intereuropeias e de construção da União.

${ }^{3}$ Podemos citar, entre outras, a obra de Marc Trachtenberg, The Craft of International History: A Guide to Method, Princeton, Princeton University Press, 2006; a de Ennio Di Nolfo, Prima lezione di storia delle relazioni internazionali, Florença, Editori Laterza, 2006 ou Concepts Histories and Theories of International Relations for the 215t century. Regional and National Approaches, dirigida por José Flávio Sombra Saraiva, Brasília, IBRI, 2009. 4Pierre Renouvin, Jean-Baptiste Duroselle, Introduction à l'histoire des relations internationales, 4. ed., Paris, A. Colin, 1991 (originalmente publicado em 1964), p. 1. 
Infelizmente, a reflexão à qual nós somos aqui convidados deve ser contida pelos limites próprios de uma resenha. Estas acanhadas poucas linhas dificilmente dariam conta de resumir tal obra de síntese, de grande densidade, longa, de quase 800 páginas e verdadeira substituta da Introduction. Sem poder eliminar o risco das escolhas arbitrárias, alguns capítulos foram eleitos para análise, pois ilustram melhor do que outros a evolução da disciplina. Esses apresentam temas revisitados ou novos e pretendem instigar os leitores a um estimulante exame do conjunto da obra.

Logo no segundo capítulo, sobre as relações entre HRI e teoria política ligada à área, Robert Frank nos faz lembrar o quanto a obra de 1964 foi importante para consolidar a importância da disciplina histórica no estudo das relações internacionais. Frank, mostrando rigor de análise, tampouco se esquece das controvérsias entre historiadores e cientistas políticos sobre o valor ou a eficácia relativa dos métodos quantitativos, das abstrações teóricas ou da linguagem matemática, em oposição às abordagens ditas qualitativas e que se pautam quase que absolutamente por análises empíricas. Uma das poucas obras da escola francesa traduzida para o português, o Tout Empire Périra. Vision théorique des relations internationales, de Jean-Baptiste Duroselle, foi uma importante testemunha dessa polêmica nos últimos 50 anos. ${ }^{5}$

Se Duroselle havia então se lançado em um exercício raro entre seus colegas (de encontrar meios de diálogo entre as duas disciplinas), o fez ainda com muita reticência e cuidado, reivindicando o primado do método histórico sobre teorias construídas, segundo ele, "artificialmente" e que não contemplariam a complexidade e a irracionalidade humana, nem levariam em consideração a historiografia existente. Sua intenção, então, foi de reafirmar o papel da História como pilar central dos estudos sobre as relações internacionais contemporâneas, iniciativa que teve seus méritos sem, entretanto, afastar as críticas. ${ }^{6}$

Ainda que Frank tenha guardado legítima prudência quanto ao uso acrítico das teorias e que reconheça a dificuldade do historiador em lidar com seu inerente "ecletismo teórico" quando diante da tarefa de trabalhar com conceitos abstratos, ${ }^{7}$ ele as defende como ferramenta "preciosa" para a pesquisa histórica. Frank não só prega uma abordagem "empírico-explicativa" da HRI, mas também defende que, "mais do que as teorias, os conceitos constituem a principal riqueza que o historiador pode encontrar nas outras ciências sociais" (p. 16, p. 41). No uso desses, ele continua, o historiador não pode esquecer da especificidade de seu métier: preservar a pesquisa empírica

\footnotetext{
${ }_{5}^{5}$ Paris, Publications de la Sorbonne, 1981. A segunda edição (Paris, A. Colin, 1992) foi traduzida no Brasil pela Editora da UnB e pela Imprensa Oficial do Estado de São Paulo, em 2000, com o título Todo Império Perecerá. ${ }^{6}$ Marcel Merle, "La problématique de létude des relations internationales en France", Revue française de science politique, ano 3,1983, p. 403-427.

${ }^{7} \mathrm{O}$ autor chega mesmo a lembrar de sua proposta, publicada em 2003, de se pensar um "real-idealismo dialético ou histórico" como meio de melhor analisar questões de "guerra e paz" (Robert Frank, "Penser historiquement les relations internationales,"Annuaire français de relations internationales, vol. 4, 2003, p. 42-65).
} 
apoiando-se nos arquivos ${ }^{8}$ e verificando "a validade dos conceitos à luz das realidades e percepções de cada época” (p. 82).

Mais à frente, no décimo quinto capítulo, o autor oferece aos leitores a oportunidade de desenvolver uma reflexão sobre um tema, em 1964, ainda longe de ser considerado por Renouvin e Duroselle como formativo das "forças profundas" da HRI: a opinião pública. Nessa época, as ditas "manifestações de opinião" eram consideradas nada mais que reflexo das condições demográficas, dos interesses econômicos ou financeiros e das tendências da mentalidade coletiva que, essas sim, deveriam ser estudadas. ${ }^{9}$ Mostrando, porém, quão rapidamente tal abordagem tornar-se-ia ultrapassada, os próprios exemplos escolhidos por Duroselle, à época, para sustentar suas hipóteses datavam de antes do desenvolvimento das mídias de massa. ${ }^{10}$

\section{Difícil não reconhecer na obra um precioso instrumento de reflexão metodológica e epistemológica para estudantes e professores}

Já Frank mostra quanto o progresso técnico mudou o papel da imprensa e a capacidade da opinião publica de influenciar os processos de tomada de decisão ao longo do século XX. O historiador passou, então, antes mesmo de se lançar nos evidentes desafios que a internet impõe, a analisar as questões levantadas pelo rádio, pelos jornais ou pela televisão, antes esquecidos pela disciplina. ${ }^{11}$ As ferramentas que os historiadores desde então construíram com a ajuda das outras Ciências Humanas permitiram analisar, de forma nova, noções de "representações, imaginários, identidades e culturas", para, enfim, avaliar melhor o papel das "mentalidades" nas relações internacionais (p. 346). O refinamento dos conceitos compondo a noção de mentalidade coletiva (primeiro, com as "atitudes mentais estáveis" e as "atitudes mentais passageiras", p. 352-355; em seguida, com as "representações" e "imaginários sociais", p. 355-370) permitiu à HRI entender que, se antes era claro o recurso à informação na luta para conservar ou conquistar poder, hoje, essa estratégia indireta tornou-se sistemática. Voilà toda a importância do tema.

Dois capítulos mais à frente, Frank aprofunda a análise de um campo que certamente veio alargar a complexidade das forças profundas preconizadas

\footnotetext{
${ }^{8}$ O capítulo 3, elaborado por Jean-Claude Allain, é todo dedicado às "fontes do historiador".

9Pierre Renouvin; Jean-Baptiste Duroselle, Introduction à l'histoire des relations internationales, 4. ed., Paris, A. Colin, 1991 (originalmente publicado em 1964), p. 3.

10/dem, Ibidem, p. 401 et seq

${ }^{11}$ Interessante notar a difusão de encontros sobre o tema, como o seminário Jean d’Arcy. La communication au service des droits de l'homme, 1913-1983, tratando do início da televisão no país e de sua importância para as relações internacionais (realizado em Paris, em 2012, tendo Robert Frank como conselheiro científico), e também a importância da exploração de arquivos, como os do Instituto Nacional do Audiovisual Francês.
} 
por Renouvin, sobretudo aquela das relações culturais: o da internacionalização do esporte e da diplomacia esportiva. Se esforços já vinham sendo concentrados no tema desde os anos 1980, ${ }^{12}$ esse "reflexo cultural das relações de forças geopolíticas e da vida internacional”, como diz Frank, ganhou uma dimensão política tanto como arma de soft power, quanto meio de aproximação entre os povos desde o momento em que se tornou parte da cultura de massa e se internacionalizou (p. 387-388).

Sobre muitos aspectos, o historiador francês serve-se dos ensinamentos de Pierre Milza $^{13}$ para lembrar que a história do esporte se associou a diversas questões geopolíticas, ao imperialismo, às aspirações pela paz perpétua, à emergência dos nacionalismos, à cultura de massas, a símbolos, a rituais, a tensões. Assim, Frank ressalta que o tema pode muito bem servir às novas gerações de historiadores como espelho das relações internacionais do século XX. Afinal, quem contestaria hoje a existência de questões políticas internacionais nos Jogos Olímpicos de 1936, 1972, 1980 ou 1984 (p. 391-396), ou nos Jogos da Commonwealth britânica (p. 400-403)?

Verdadeiro manifesto pela disciplina, o livro não procura estabelecer inflexivelmente os limites da pesquisa futura. Ele reconhece que campos praticamente ainda não explorados podem surgir e problemas insistentes, desaparecer no futuro próximo. O objetivo maior é fazer um balanço. Se Renouvin e Duroselle incentivaram os historiadores a se lançar no estudo das relações internacionais na época contemporânea, a rápida evolução do sistema internacional modificou vários aspectos da realidade que os cercava à época. Diferentes problemas mudaram de natureza, a composição das relações de força se transformou e o número de atores se multiplicou. Difícil esperar que alguém hoje defenda uma HRI detendo-se somente em atos e em decisões dos homens de Estado ou, menos ainda, a perspectivas estritamente nacionais de relações internacionais.

Porém, mesmo Renouvin já tendo defendido ser a abordagem estadocentrada insuficiente, Frank lembra que o precursor da disciplina raras vezes conseguiu levar a cabo a aplicação de seus enunciados, o que, em muitas oportunidades, deu razão a Marc Bloch e às gerações influenciadas pelos Annales de não distinguir muito bem em que a HRI seria renovadora face à antiga História Diplomática.

Em um esforço para manter a escola francesa na vanguarda da disciplina e mostrar que ela tenta não perder o seu élan, ${ }^{14}$ Robert Frank não só provocou uma série de reflexões a esse respeito nessa obra (como na segunda parte intitulada "O nacional, o internacional e o transnacional"), como também

\footnotetext{
${ }^{12}$ Frank nos lembra do número especial 38, de 1984, da revista Relations Internationales, coordenada por Pierre Milza e intitulado "Esporte e relações internacionais", mas também do Congresso de mesmo título organizado em Metz, em 1993, cujas atas foram publicadas por Pierre Arnaud e Alfred Wahl, e dos números 111 e 112, também da Relations Internationales, de 2002, sob o título "Movimento olímpico e relações internacionais."

13Pierre Milza, "Sport et relations internationales," Relations Internationales, n. 38, 1984, p. 155-174.

${ }^{14}$ Norma Breda dos Santos, "História das Relações Internacionais no Brasil: esboço de uma avaliação sobre a área”, História, vol. 24, n. 1, São Paulo, 2005, p. 17.
} 
completou seu esforço ao lançar simultaneamente a revista Monde(s), ${ }^{15}$ abrindo uma porta importante para que seus colegas franceses possam dialogar com a Global History ${ }^{16}$ e com a História Transnacional. Essa, segundo Frank,

ao privilegiar a análise das 'transferências' e das 'circulações' através das fronteiras [...], valoriza uma série de dinâmicas sociais que, há muito tempo, vêm transformando o sistema de nações e que, há três ou quatro décadas, chega mesmo a colocá-lo em questão (p. 105-106).

Assim nasceu um novo canal de diálogo, a primeira revista francesa de História Global, aspirando a "colocar em perspectiva histórica as conexões e as interferências entre as sociedades." ${ }^{17} \mathrm{O}$ esforço é claro no sentido de tirar a produção e as perspectivas históricas do eurocentrismo ou do nacionalismo metodológico (simbolicamente, e caso raro no país, a revista aceita publicações em inglês, que, por sua vez, é reconhecido como "a língua global"). ${ }^{20}$

Em razão do dinamismo inerente às publicações periódicas, que conseguem corrigir seus rumos ainda em vida, Monde(s) tem a missão de tornar ainda mais relativo um resistente eurocentrismo que, apesar dos esforços, conseguiu fazer-se presente mesmo em certas partes da obra de Frank. De fato, apesar do esforço, esse viés pode ser notado não só nas referências bibliográficas, mas também, por exemplo, na explicação histórica sobre a evolução da "democracia internacional" por marcos quase que exclusivamente europeus, esquecendo por completo, entre outras, a experiência interamericana (p. 690). Em outra passagem, marcante para os brasileiros, a obra se esquece das reticências da delegação do Brasil à Resolução 1973 do Conselho de Segurança da ONU sobre a Líbia, ao apontar como únicas, dentre as dos "países democráticos" quando da votação, as hesitações dos alemães (p. 692).

Apesar dessas ressalvas, difícil não reconhecer na obra um precioso instrumento de reflexão metodológica e epistemológica para estudantes e professores e um meio para aqueles interessados em conhecer mais de perto os trabalhos desenvolvidos na França no início do século XXI. Ao também englobar novos temas de estudo, Frank abre caminhos, indica direções e áreas de pesquisa e dá lições valiosas de rigor científico para os que neles se aventuram.

\footnotetext{
${ }^{15}$ Nota-se o esforço na montagem do comitê científico (composto, entre outros, por Frederik Cooper, Matthew Connelly, Emma Rothschild e Odd Arne Westad) de mudar uma realidade segundo a qual os historiadores franceses, internacionalistas em seu campo de estudo, raramente (e paradoxalmente) o são na maneira de escrever (Monde(s), Histoire, Espaces, Relations. Nouvelle revue d'histoire globale et lieu d'expression pour les tendances neuves de l'histoire internationale, publicada por A. Colin com ISSN 1234-1234).

${ }^{16}$ Interessante notar o impacto na França (p. 278) do texto militante de Thomas Zeiler intitulado "Just Do It! Globalization for Diplomatic Historians", publicado no vol. 25, n. 4, em 2001, da Diplomatic History.

${ }^{17}$ Robert Frank, "Avant-propos - Pourquoi une nouvelle revue?", Monde(s), n. 1, maio 2012, p. 8.

2oldem, Ibidem, p. 9.
} 